\title{
De Wet zorgplicht kinderarbeid nader belicht
}

\author{
H. Koster
}

\section{Inleiding}

Voor Nederlandse ondernemingen is maatschappelijk verantwoord ondernemen (MVO) een steeds belangrijker aandachtsgebied. MVO gaat erover dat ondernemingen bij hun streven naar winst rekening dienen te houden met menselijke en maatschappelijke belangen. MVO ziet op thema's als mensenrechten, milieu, arbeidsomstandigheden, consumentenaangelegenheden, gemeenschapsontwikkeling en eerlijk zakendoen. ${ }^{1}$ Ondernemingen hebben bepaalde verantwoordelijkheden op het terrein van MVO. In de praktijk zullen de culturele en ethische achtergronden van (de mensen in de) ondernemingen ervoor zorgen dat zij MVO op een manier inkleuren die op hun belangen en prioriteiten aansluit. ${ }^{2}$ Van belang is voorts dat MVO uitgaat van een multi-stakeholder perspectief. Ondernemingen hebben niet slechts verantwoordelijkheden tegenover aandeelhouders, maar ook jegens andere stakeholders zoals werknemers, klanten en toeleveranciers. Inmiddels heeft MVO ook tot wetgeving geleid. Op 12 mei 2019 stemde de Eerste Kamer namelijk in met de Wet zorgplicht kinderarbeid. ${ }^{3}$ Deze wet verplicht bedrijven te verklaren dat zij het nodige doen om kinderarbeid te voorkomen. ${ }^{4}$ Dit is een belangrijk aandachtsgebied. De Internationale Arbeidsorganisatie (ILO) heeft in 2017 bekendgemaakt dat wereldwijd ongeveer 152 miljoen kinderen kinderarbeid verrichten. ${ }^{5}$ Uit onderzoek in opdracht van de ministeries van Buitenlandse Zaken en Economische Zaken en Klimaat blijkt dat kinderarbeid een risico is in elf van de dertien onderzochte risicosectoren. ${ }^{6}$ Kinderarbeid is wijdverbreid in sectoren zoals de textiel-, leer-, landbouw-, visserij-, veeteelt- en mijnbouwsector. Nederland sluit zich met de totstandkoming van deze wet aan bij een wereldwijde trend richting wettelijke verplichtingen voor bedrijven die moeten zorgen dat zij mensenrechten respecteren. ${ }^{7}$ De Wet zorgplicht kinderarbeid wordt naar

1 T.E. Lambooy, Corporate Social Responsibility. Legal and Semi-Legal Frameworks Supporting CSR (diss. Leiden) (Uitgaven vanwege het Instituut voor Ondernemingsrecht 77), Deventer: Kluwer 2010, p. 6.

2 Lambooy 2010, p. 9-11.

3 Voorstel van wet van lid Kuiken houdende de invoering van een zorgplicht ter voorkoming van de levering van goederen en diensten die met behulp van kinderarbeid tot stand zijn gekomen. De Tweede Kamer nam op 7 februari 2017 dit initiatiefwetsvoorstel aan.

4 Met de wettelijke regeling wordt invulling gegeven aan de 'duty to protect', die de OESO overheden toedicht.

5 Verslag van een deskundigenbijeenkomst van 24 oktober 2017. Zie Kamerstukken I 2017/18, 34506, K. Uit de memorie van toelichting blijkt dat men inmiddels uitgaat van 168 miljoen kinderen. Zie Kamerstukken II 2016/17, 34506, nr. 6.

6 KPMG Sector Risico Analyse, 2015.

7 Zie Strategies for Responsible Business Conduct, een rapport van december 2018 opgesteld door PWC voor het ministerie van Buitenlandse Zaken. 
verwachting van kracht op 1 januari 2022. ${ }^{8}$ De periode tot inwerkingtreding zal worden gebruikt voor het opstellen van de nadere regelgeving. ${ }^{9}$ In dit artikel onderzoek ik de Wet zorgplicht kinderarbeid (hierna: wet) en analyseer ik wat de consequenties (kunnen) zijn van deze wet voor het bedrijfsleven. ${ }^{10}$

\section{Achtergronden}

Het doel van dit wetsvoorstel is om ervoor te zorgen dat consumenten ervan uit kunnen gaan dat de goederen en diensten die zij op de Nederlandse markt kopen, verkocht worden door ondernemingen die er binnen hun mogelijkheden redelijkerwijs alles aan doen om te voorkomen dat hun goederen en diensten tot stand komen met gebruikmaking van kinderarbeid. ${ }^{11}$ Met de wettelijke regeling wordt beoogd dat ondernemingen dienen aan te tonen dat zij, met inachtneming van omvang, capaciteit en type sector, redelijkerwijs voldoende doen om kinderarbeid te voorkomen in hun productieketens. ${ }^{12}$ Op dit moment gelden voor ondernemingen al de richtlijnen van de Organisatie voor Economische Samenwerking en Ontwikkeling (OESO), waaronder regels op het gebied van kinderarbeid. ${ }^{13}$ Door het ontbreken van toezicht of controle is nu niet vast te stellen of ondernemingen daadwerkelijk handelen overeenkomstig die richtlijnen. Op basis van de wet dienen ondernemingen die goederen of diensten aan Nederlandse eindgebruikers verkopen of leveren te verklaren dat zij gepaste zorgvuldigheid betrachten om te voorkomen dat die goederen of diensten met behulp van kinderarbeid tot stand komen. De aard van de verklaring is gebaseerd op doorlopende inspanningen. De onderneming die verklaart gepaste zorgvuldigheid te betrachten ten aanzien van kinderarbeid, verklaart daarmee een doorlopend beleid te hebben en uit te voeren waarmee (risico's op) kinderarbeid in haar productieketen in kaart wordt gebracht, voorkomen dan wel aangepakt. ${ }^{14}$ In de kern verplicht de wet ondernemingen invulling te geven aan de OESO-richtlijnen bij de aanpak van kinderar-

8 Zie https://ondernemersplein.kvk.nl/wet-zorgplicht-kinderarbeid/.

9 Van belang is voorts dat op grond van art. 11 van de wet deze niet van toepassing is op de levering van goederen of diensten waarvoor de verplichting is aangegaan voor de datum van uitgifte van het Staatsblad waarin zij wordt geplaatst, tot het tijdstip waarop de verplichting komt te vervallen ingevolge een beding dat voor de datum van uitgifte van het Staatsblad waarin deze wet wordt geplaatst is overeengekomen, doch niet later dan vijf jaar na het tijdstip van inwerkingtreding van deze wet.

10 Op basis van art. 10 van de wet zendt de minister voor Buitenlandse Handel en Ontwikkelingssamenwerking binnen vijf jaren na de inwerkingtreding van de wet aan de StatenGeneraal een verslag over de doeltreffendheid en de effecten van de wet in de praktijk.

11 Zie Kamerstukken II 2016/17, 34506, nr. 8 (Nota naar aanleiding van het verslag).

12 Zie Kamerstukken II 2016/17, 34506, nr. 6.

13 Voor de Nederlandse overheid zijn op het gebied van Internationaal Maatschappelijk Verantwoord Ondernemen (IMVO) de OESO-richtlijnen voor Multinationale Ondernemingen leidend. Zie www.oesorichtlijnen.nl/oeso-richtlijnen/a/algemene-informatie-oeso-richtlijnen/documen ten/brochure/201/12/8/volledige-tekst-oeso-richtlijnen. Zie Kamerstukken II 2016/17, 34506, nr. 6.

14 Brief van het Tweede Kamerlid Kuiken van 12 oktober 2018 aan de Voorzitter van de Eerste Kamer der Staten-Generaal. Zie Kamerstukken I 2018/19, 34506, M. 
beid. Omdat veel ondernemingen nu geen weet hebben van de OESO-richtlijnen en er niets mee doen, ${ }^{15} \mathrm{zal}$ deze wettelijke regeling het bewustzijn vergroten en de handelingsbereidheid vergroten. ${ }^{16}$

De gedachte is dat deze wet ertoe leidt dat ondernemingen niet langer concurrentievoordeel kunnen behalen door kinderarbeid in hun keten toe te staan. ${ }^{17}$ Ondernemingen die bewust of onbewust kinderarbeid in hun keten toelaten, dienen na inwerkingtreding van de wet redelijkerwijs de risico's op kinderarbeid in hun keten in kaart te brengen, deze naar hun kunnen te mitigeren en verantwoord op te treden indien zij kinderarbeid constateren. ${ }^{18}$ Het betreft evenwel geen volledige ketentransparantie, maar een minder vergaande gepaste zorgvuldigheid die geldt voor de gehele keten. ${ }^{19}$ De onderneming garandeert niet dat er geen kinderarbeid plaatsvindt, maar verklaart wat zij binnen haar mogelijkheden onderneemt om kinderarbeid in kaart te brengen, te voorkomen en/of uit te bannen. ${ }^{20}$

\section{De vormgeving van de wettelijke regeling}

De wettelijke regeling is gericht op het tegengaan van kinderarbeid. In de wet is kinderarbeid nader gedefinieerd. Van kinderarbeid is namelijk sprake bij elke vorm van arbeid in en buiten dienstverband verricht door personen die de leeftijd van 18 jaar nog niet hebben bereikt en die behoort tot de ergste vormen van kinderarbeid, bedoeld in art. 3 Verdrag betreffende de ergste vormen van kinderarbeid 1999. ${ }^{21}$ Voorts is sprake van kinderarbeid in het geval dat de arbeid plaatsvindt op het grondgebied van een Staat die partij is bij het Verdrag betreffende de minimumleeftijd 1973, bij elke vorm van arbeid die krachtens de wetgeving van die Staat ter uitvoering van dat verdrag is verboden. ${ }^{22}$ Daarnaast geldt dat als de arbeid plaatsvindt op het grondgebied van een Staat die geen partij is bij het Verdrag betreffende de minimumleeftijd 1973 dat onder kinderarbeid tevens wordt

Elk OESO-lid kent een Nationaal Contact Punt (NCP). Deze aan de OESO gelieerde NCP's ondersteunen bedrijven bij de toepassing van de OESO-richtlijnen door allerlei vormen van informatieverschaffing. Daarnaast dienen de NCP's als meldpunten voor klachten van personen, maatschappelijke organisaties en bedrijven over de toepassing van de richtlijnen. Het NCP kan tussen de melders en de betreffende bedrijven bemiddelen om tot een oplossing te komen. Als het overleg tussen de partijen niet tot een gezamenlijke oplossing leidt, kan het NCP een verklaring uitbrengen over (het gebrek aan) de naleving van de OESO-richtlijnen en aanbevelingen richting de betreffende onderneming doen. Deze verklaring kan worden gepubliceerd en onder de aandacht gebracht worden van de uitvoerders van overheidsregelingen en institutionele beleggers. Dergelijke NCP-procedures kennen evenwel geen juridische consequenties waaraan directe rechtsgevolgen kunnen worden verbonden. Zie hierover Kamerstukken II 2016/17, 34506, nr. 6.

16 Zie Kamerstukken II 2016/17, 34506, nr. 8 (Nota naar aanleiding van het verslag).

17 Zie Kamerstukken II 2016/17, 34506, nr. 8 (Nota naar aanleiding van het verslag).

18 Zie hierover Kamerstukken II 2016/17, 34506, nr. 6.

19 Zie Kamerstukken II 2016/17, 34506, nr. 8 (Nota naar aanleiding van het verslag).

20 Brief van het Tweede Kamerlid Kuiken van 12 oktober 2018 aan de Voorzitter van de Eerste Kamer der Staten-Generaal. Zie Kamerstukken I 2018/19, 34506, M.

21 Art. 2 lid 1 onder a Wet zorgplicht kinderarbeid.

22 Art. 2 lid 1 onder b Wet zorgplicht kinderarbeid. 
verstaan: (1) elke vorm van arbeid in en buiten dienstverband verricht door personen die leerplichtig zijn of die de leeftijd van 15 jaar nog niet hebben bereikt; en (2) elke vorm van arbeid in en buiten dienstverband verricht door personen die de leeftijd van 18 jaar nog niet hebben bereikt, voor zover die arbeid krachtens de aard van de arbeid of de omstandigheden waaronder deze wordt uitgevoerd de gezondheid, de veiligheid of de zedelijkheid van jeugdige personen in gevaar kan brengen. ${ }^{23}$ In deze beide laatste gevallen ${ }^{24}$ is evenwel geen sprake van kinderarbeid indien het lichte werkzaamheden betreft, als bedoeld in art. 7 lid 1 Verdrag betreffende de minimumleeftijd, 1973, die gedurende ten hoogste 14 uur per week worden verricht door personen die de leeftijd van 13 jaar hebben bereikt.

Op basis van de wet dient elke in Nederland gevestigde onderneming die goederen of diensten aan Nederlandse eindgebruikers verkoopt of levert, schriftelijk te verklaren dat zij gepaste zorgvuldigheid betracht om te voorkomen dat die goederen of diensten met behulp van kinderarbeid tot stand komen. Dezelfde verplichting geldt ook voor niet in Nederland gevestigde ondernemingen die goederen of diensten aan Nederlandse eindgebruikers verkopen of leveren. De onderneming dient de daartoe vereiste verklaring nadat de onderneming is ingeschreven in het handelsregister onverwijld aan de toezichthouder te laten toekomen. Ondernemingen die reeds zijn ingeschreven bij het handelsregister zenden de verklaring binnen zes maanden na het in werking treden van de wet toe aan de toezichthouder. Een onderneming die niet in het Europese deel van Nederland is gevestigd en die niet wordt ingeschreven in het handelsregister, dient de verklaring aan de toezichthouder te zenden binnen zes maanden nadat de onderneming voor de tweede keer in een bepaald jaar goederen of diensten levert aan eindgebruikers in Nederland. ${ }^{25}$ De ondernemingen die leveren aan de eindgebruiker zullen vanwege de vereiste gepaste zorgvuldigheid de ondernemingen eerder in de keten moeten betrekken bij het naleven van hun zorgplicht. De handel tussen ondernemingen en het enkele vervoer van goederen vallen dus buiten de reikwijdte van de wettelijke regeling. ${ }^{26}$ De toezichthouder publiceert de verklaringen in een openbaar register op zijn website. De onderneming die alleen goederen of diensten afneemt van ondernemingen die een dergelijke verklaring hebben afgegeven, betracht eveneens gepaste zorgvuldigheid doch hoeft zelf geen verklaring af te geven. De af te geven verklaring is onbeperkt geldig, tenzij de eisen die gesteld worden aan die verklaring veranderen. Het is daarmee in beginsel een eenmalige verklaring. Het is aan de onderneming zelf om er zorg voor te dragen dat ook als haar keten, product of dienst verandert, zij blijft voldoen aan hetgeen zij heeft verklaard. Als de invulling van gepaste zorgvuldigheid in de loop der jaren verandert, verandert ook de manier waarop ondernemingen invulling dienen te geven

Art. 2 lid 1 onder c Wet zorgplicht kinderarbeid.
Als opgenomen in art. 2 lid 1 onder c Wet zorgplicht kinderarbeid.

Bij of krachtens AMvB kunnen uitzonderingen worden toegestaan voor het tijdstip waarop de verklaring wordt aangeleverd en kunnen nadere regels worden gesteld over inhoud en vorm van de verklaring.

Zie Kamerstukken II 2016/17, 34506, nr. 6. 
aan de verklaring. Ondernemingen die geen goederen of diensten meer leveren aan eindgebruikers in Nederland, kunnen hun verklaring op elk gewenst moment intrekken.

In de wettelijke regeling is opgenomen hoe ondernemingen invulling geven aan deze zorgplicht. Dit geschiedt door het uitvoeren van een onderzoek en het opstellen van een plan van aanpak, indien uit het onderzoek blijkt dat er een redelijk vermoeden is dat goederen of diensten tot stand kunnen zijn gekomen met gebruikmaking van kinderarbeid. Het onderzoek is gericht op bronnen die voor de onderneming redelijkerwijs kenbaar en raadpleegbaar zijn. ${ }^{27}$

De onderneming die onderzoekt of er een redelijk vermoeden bestaat dat de te leveren goederen of diensten met behulp van kinderarbeid tot stand zijn gekomen en die in geval van het bestaan van een redelijk vermoeden, een plan van aanpak vaststelt en uitvoert, ${ }^{28}$ betracht gepaste zorgvuldigheid. Daarnaast geldt dat een onderneming die goederen of diensten afneemt van een onderneming die een verklaring op basis van de wet heeft afgegeven, ook gepaste zorgvuldigheid betracht ten aanzien van de desbetreffende goederen of diensten.

Een redelijk vermoeden bestaat indien duidelijke aanwijzingen bestaan dat de desbetreffende goederen (mede) tot stand zijn gekomen in landen waarvan bekend is dat vergelijkbare producten of productieprocessen met behulp van kinderarbeid een rol spelen. ${ }^{29}$ Dit gegeven vormt op zich voldoende aanleiding, zo volgt uit de memorie van toelichting, om met leveranciers of fabrikanten in contact te treden en maatregelen te nemen om betrokkenheid van kinderarbeid uit te sluiten. ${ }^{30}$ De minister voor Buitenlandse Handel en Ontwikkelingssamenwerking kan voorts een gezamenlijk plan van aanpak dat tot doel heeft om daarbij aangesloten ondernemingen gepaste zorgvuldigheid te laten betrachten om te voorkomen dat goederen of diensten met behulp van kinderarbeid tot stand komen, en dat tot stand komt tussen één of meer maatschappelijke organisaties, organisaties van werknemers of organisaties van werkgevers, goedkeuren. Een onderneming die handelt in overeenstemming met een dergelijk goedgekeurd gezamenlijk plan van aanpak, betracht gepaste zorgvuldigheid. Als bedrijven zich derhalve aansluiten bij een convenant op het terrein van Internationaal Maatschappelijk Verantwoord Ondernemen (IMVO) of een ander IMVO-initiatief hoeven zij niet zelf het wiel uit te vinden, maar kunnen zij profiteren van de daar aanwezige kennis en ervaring.

Er zal een toezichthouder worden aangewezen die belast is met het toezicht op de naleving van het bij of krachtens de wet bepaalde. Als toezichthouder is genoemd dat de Autoriteit Consument en Markt (ACM) als zodanig zou kunnen worden

27 Art. 5 lid 2 Wet zorgplicht kinderarbeid.

28 Bij of krachtens AMvB worden, met inachtneming van de ILO-IOE Child Labour Guidance Tool for Business, nadere eisen gesteld aan het onderzoek en aan het plan van aanpak. Hiermee wordt niet-bindende regelgeving door middel van wetgeving verbonden met dwingend recht.

29 Zie hierover Kamerstukken II 2016/17, 34506, nr. 6.

30 Zie hierover Kamerstukken II 2016/17, 34506, nr. 6. 
aangewezen, ${ }^{31}$ opdat de link met het doel, namelijk het beschermen van consumenten, helder is. De toezichthouder dient na een klacht te toetsen of de desbetreffende onderneming waartegen een klacht is ingediend gepaste zorgvuldigheid heeft betracht. Iedere natuurlijke persoon en rechtspersoon wiens belangen geraakt zijn door het doen of laten van een onderneming bij de naleving van het bepaalde bij of krachtens deze wet, kan daarover een klacht indienen bij de toezichthouder. Daarvoor dient wel sprake te zijn van een concrete aanwijzing voor niet-naleving van het bepaalde bij of krachtens deze wet door een aanwijsbare partij. Een klacht kan voorts pas door de toezichthouder in behandeling worden genomen, nadat deze door de onderneming is afgehandeld, dan wel zes maanden na indiening van de klacht bij de onderneming zonder dat deze is afgehandeld. De toezichthouder dient de informatie te beoordelen die ondernemingen en klagers aandragen. Klagers kunnen door getuigen, bewijzen, rapporten, onderzoeken en andere bewijsmiddelen aantonen dat er kinderarbeid in een bepaald goed of dienst zit. Is hiervan sprake, dan kunnen ondernemingen hun plan van aanpak om kinderarbeid in dat goed of die dienst te voorkomen, overleggen en laten zien hoe dit plan van aanpak in de praktijk wordt en is gebracht. Als een onderzoek of plan van aanpak niet voldoet, kan de toezichthouder een bindende aanwijzing geven. De toezichthouder kan de overtreder een termijn stellen waarbinnen de aanwijzing moet worden opgevolgd. Als die aanwijzing niet wordt opgevolgd, kan een boete worden opgelegd. Bij een tweede boeteoplegging binnen vijf jaar voor eenzelfde overtreding door de onderneming, begaan in opdracht of onder feitelijke leiding van eenzelfde bestuurder, kan na een procedure bij de strafrechter een strafrechtelijke veroordeling volgen.

Om de rechtszekerheid voor bedrijven te waarborgen zal per algemene maatregel van bestuur $(\mathrm{AMvB})$ nader worden ingegaan op de voorwaarden voor het naleven van deze wet. Deze voorwaarden zullen worden gebaseerd op de OESOrichtlijnen. Er zijn drie punten die in elk geval nader ingevuld moeten worden bij $\mathrm{AMvB}$, namelijk: (1) het aanwijzen van de toezichthouder; (2) eisen aan het ketenonderzoek en het gerelateerde plan van aanpak; (3) vrijstelling van bepaalde categorieën ondernemingen. ${ }^{32}$

31 De ACM is volgens de initiatiefnemer van het wetsvoorstel in staat om het toezicht op deze initiatiefwet op zich te nemen. Hiervoor zou zij kennis en capaciteit moeten aantrekken. Deze kennis is onder meer voorhanden bij het Nationaal Contactpunt van de OESO en de Sociaal-Economische Raad als nauw betrokken partner bij het imvo-convenantenbeleid. Volgens de initiatiefnemer behoort het oprichten van een nieuwe toezichthouder eveneens tot de mogelijkheden. Het uiteindelijke besluit hierover is op verzoek van de regering-Rutte II per AMvB aan de regering gelaten. Zie hierover de brief van het Tweede Kamerlid Kuiken van 9 april 2019 aan de Voorzitter van de Eerste Kamer der Staten-Generaal, Kamerstukken I 2018/19, 34506, Q.

32 Brief van de minister voor Buitenlandse Handel en Ontwikkelingssamenwerking van 17 juli 2017 aan de Voorzitter van de Eerste Kamer der Staten-Generaal. Zie Kamerstukken I 2016/17, 34506, G. 


\section{De consequenties voor het bedrijfsleven}

De Wet zorgplicht kinderarbeid verplicht bedrijven te verklaren dat zij het nodige doen om kinderarbeid te voorkomen. Nederland sluit zich met de totstandkoming van deze wet aan bij een wereldwijde trend richting wettelijke verplichtingen voor bedrijven die moeten zorgen dat zij mensenrechten respecteren. ${ }^{33} \mathrm{Na}$ inwerkingtreding van deze wet dienen bedrijven die goederen of diensten aan Nederlandse eindgebruikers verkopen of leveren, schriftelijk te verklaren dat zij gepaste zorgvuldigheid betrachten om te voorkomen dat die goederen of diensten met behulp van kinderarbeid tot stand komen. De wettelijke regeling heeft de vormgeving van deze verklaring niet in detail afgebakend. ${ }^{34}$ Het staat ondernemingen derhalve vrij zo veel informatie als wenselijk in de verklaring op te nemen. Ondernemingen zullen hun weg moeten vinden hoe invulling te geven aan deze vage zorgplichtnorm. Deze verklaringen worden vervolgens openbaar gemaakt in een openbaar online register en de toezichthouder gaat toezicht houden op naleving. Door publicatie van deze verklaringen krijgen consumenten, inkopers en andere geïnteresseerden inzicht in de verschillende aanpakken en/of waarborgen die ondernemingen willen delen. De gedachte is dat dit zowel transparantie over eerlijke handel stimuleert als een nieuwe mogelijkheid voor ondernemingen om zich te onderscheiden.

Bedrijven zullen er mogelijk voor kiezen om hun zorgplicht contractueel op te leggen aan de bedrijven die aan hen goederen of diensten leveren. Het lijkt mij evenwel dat een leverancier niet per se alleen zal mogen vertrouwen op verklaringen van fabrikanten of toeleveranciers dat producten zonder kinderarbeid tot stand zijn gekomen. Immers, uitgangspunt is en blijft dat de onderneming een eigen passende zorgplicht heeft. De wet bepaalt daarover dat ondernemingen aan die zorgplicht uitvoering geven door het uitvoeren van onderzoek. Het onderzoek is gericht op bronnen die voor de onderneming redelijkerwijs kenbaar en raadpleegbaar zijn. ${ }^{35}$ Alleen maar afgaan op contractuele afspraken zal in de regel dus niet voldoen. Bedrijven kunnen overigens wel met hun toeleveranciers afspreken dat die de verklaring indienen bij de toezichthouder, zodat zij dat niet hoeven te doen. De onderneming die alleen goederen of diensten afneemt van ondernemingen die een zorgplichtverklaring hebben afgegeven, dient niettemin nog steeds gepaste zorgvuldigheid te betrachten. ${ }^{36}$

De concrete gevolgen en lasten voor het bedrijfsleven zullen met name worden bepaald door de precieze invulling van de zorgplicht, waaronder de omvang van het vereiste onderzoek naar de herkomst van producten en de precieze invulling van het vereiste plan van aanpak.

33 Zie Strategies for Responsible Business Conduct, een rapport van december 2018 opgesteld door PWC voor het ministerie van Buitenlandse Zaken.

34 Wel kunnen bij of krachtens $\mathrm{AMvB}$ nog nadere regels worden gesteld over inhoud en vorm van de verklaring.

35 Art. 5 lid 2 Wet zorgplicht kinderarbeid.

36 Art. 5 lid 1 Wet zorgplicht kinderarbeid. 
Een belangrijke vraag is hoever de zorg- en onderzoeksplicht gaat. Ziet de zorg- en onderzoeksplicht ook op de herkomst van onderdelen of grondstoffen van producten/halffabricaten? Nu de idee is dat de onderneming verklaart wat zij binnen haar mogelijkheden onderneemt om kinderarbeid in kaart te brengen, te voorkomen en/of uit te bannen, ${ }^{37}$ lijkt dit ook onderdeel uit te maken van de zorgplicht. De gedachte is immers dat de zorgplicht op de gehele leveringsketen ziet.

Het is zeker niet ondenkbaar dat in de nabije toekomst bedrijven, die dan nog niet actief bezig zijn met het tegengaan van kinderarbeid, daar door stakeholders of zelfs vanuit de publieke opinie op worden aangesproken. Uit onderzoek blijkt in elk geval dat maar liefst $96 \%$ van de consumenten het niet acceptabel vindt dat producten een lage prijs hebben omdat ze zijn gemaakt door kinderen. ${ }^{38}$ Wellicht zullen bedrijven die nog onvoldoende doen op dit terrein, daar zelfs wel in de toekomst vanuit het perspectief van maatschappelijk verantwoord ondernemen in rechte op worden aangesproken. Wat hier verder ook van zij, bedrijven zullen dienen te investeren in hun processen om gepaste zorgvuldigheid te betrachten om te voorkomen dat goederen of diensten met behulp van kinderarbeid tot stand komen. Bestuurders zullen zichzelf daarom moeten afvragen wat er gedaan moet worden, met wie ze kunnen samenwerken en op welke wijze dat kan worden vormgegeven.

Ten slotte geldt dat een actief toezicht door de raad van commissarissen op de naleving van deze wetgeving door het bestuur kan bijdragen aan het succes van deze wet.

\section{Conclusie}

De ontwikkelingen op het terrein van maatschappelijk verantwoord ondernemen zijn volop in beweging. Overheden en bedrijven krijgen hier steeds meer mee te maken. Het kabinet en de Staten-Generaal hebben deze ontwikkeling in Nederland versterkt door de aanname van de Wet zorgplicht kinderarbeid. Deze wet verplicht bedrijven te verklaren dat zij het nodige doen om kinderarbeid te voorkomen. Bedrijven zullen daarom dienen te investeren in hun processen om gepaste zorgvuldigheid te betrachten om te voorkomen dat goederen of diensten met behulp van kinderarbeid tot stand komen. 